\title{
The leverage of corporate environmental protection concepts on employee motivation
}

\author{
D. Bartik ${ }^{1}$, A. Hoeltl ${ }^{2} \&$ R. Brandtweiner ${ }^{3}$ \\ ${ }^{1}$ University of Applied Sciences BFI Vienna, Austria \\ ${ }^{2}$ Department for Management and Economics, \\ Danube University Krems, Austria \\ ${ }^{3}$ Institute of Information Management and Control, \\ Vienna University of Economics and Business, Austria
}

\begin{abstract}
Corporate environmental protection is nowadays no longer just a marketing tool or an annoying necessity for a good reputation, but for many companies an integrated element of the corporate culture and of doing business. In a case study of a company in Austria, this paper investigates a feasible additional advantage for corporate environmental protection in terms of a positive leverage on employee motivation. After giving an overview of the most important theoretical approaches and tools regarding corporate responsibility, incentives, and employee motivation, the influence of the environmental protection concept of Kommunalkredit Austria AG on the job motivation of its employees is analysed on the basis of a questionnaire covering all corporate responsibility related topics. The results show a spill-over effect of a company's increased social responsibility on the behaviour and performance of the employees.

Keywords: corporate environmental management, corporate social responsibility, environmental management system, employee motivation, stakeholder management.
\end{abstract}

\section{Introduction}

Today's companies face not only economic but more and more societal compulsion. The formation of the corresponding public opinion is supported by critical media reports and documentations as well as by nonfiction books offering black and white lists concerning the societal performance of companies. 
Thus environmental and social responsibilities have become important rules of conduct in the business world.

A company's commitment to corporate social responsibility (CSR) means a corporate policy with orientation towards strategic, long-term, and resource friendly value creation, compared to focusing exclusively on short-term profit.

Values, attitudes, and norms regarding environmental protection made public by companies do not only influence the purchase behaviour of consumers but also the motivation of the companies' employees [1]. According to the hypothesis about a better performance of employees caused by different motivation methods, the paper investigates the influence of corporate environmental protection on the employee motivation. Thus the present societal challenges for companies can be used as an opportunity for a sustainable success in business.

The paper gives an overview of the theoretical concepts of CSR, of corporate environmental management systems, and of employee motivation, as well as presenting the results of a corresponding case study of a bank in Austria, using the theoretical concepts in conjunction with interviews of employees and managers [2].

\section{Theoretical approaches}

Theoretical concepts relevant for analysing a relationship between CSR and employee motivation are presented. On the one hand stakeholder management and CSR as well as concepts of corporate environmental management, while on the other types and theories of motivation and incentives.

\subsection{Stakeholder management}

Compared to the shareholder value approach focusing predominantly on the owner of the company, stakeholder management is a much broader approach considering all internal and external economic and social interdependences. Meanwhile it's common knowledge that a good rapport with the stakeholders is essentially for a long-term and sustainable business success [3]. Stakeholders can influence actively the behaviour of a company. As different stakeholders have diverging interests, it's difficult for a company to satisfy all of them. First of all it's essential to identify the relevant stakeholders with their interests and strengths, mainly with the stakeholder analysis, in order to implement these aspects in the company's strategy [4]. A thorough involvement of the stakeholders can minimize the corporate risks possible by CSR. Further an open and transparent relationship to the stakeholders, including the employees, confirms responsible economic activity. By combining CSR and the stakeholder approach, not only can unfavorable effects be avoided, but in fact competitive advantages are created. 


\subsection{Corporate social responsibility}

There are several definitions of CSR, but the key point is a societal responsible business going beyond legal requirements. According to Schneider [5] a final definition of CSR is not possible or useful, as CSR is a "moving issue", a dynamic and for each enterprise individual process.

The European Commission published a new definition of CSR [6] as "the responsibility of enterprises for their impacts on society". Thus companies should have in place an appropriate process for "maximising the creation of shared value for their owners/shareholders and for their other stakeholders and society at large, and for identifying, preventing and mitigating their possible adverse impacts".

For the integration of CSR into the company's strategy a first starting point is the analysis of the supply chain. This helps optimising the social image and increasing the competitiveness of the company. Further a detailed analysis of the range of products is recommended. It's important that CSR is not an additional task of the company, but is integrated in the corporate strategy. CSR has to be connected closely to the core business and should be integrated directly in the management of the company [7].

CSR is a controversially discussed concept. The advantages are seen as a winwin concept for the society and the company itself [8]. Further it strengthens the relationship with the stakeholders and has a positive influence on human resource management. CSR supports the employee motivation and their satisfaction, which has a positive effect on the working atmosphere and in consequence on productivity. A more intensive communication culture enables the company to cater to the customer's wishes and needs in a better and more efficient way. Additionally CSR can create new business options and markets, and by that promote innovation. Finally CSR activities can help to improve the environmental and social balance sheet of the company. The voluntariness of the CSR approach is seen as an advantage but also as a disadvantage. Due to the lack of formal regulation, the information to stakeholders is not standardized and therefore a comparison of the CSR performance of different companies is difficult. The feasible misuse of CSR as a marketing strategy is a further issue.

Related concepts for societal responsible management are e.g. sustainable development, sustainable management, and corporate citizenship.

\subsection{Corporate environmental management}

Corporate environmental management includes all aspects of corporate environmental policy. One definition is that environmental protection is considered in all business processes including planning, implementation and controlling [9]. The business objective environmental protection is set in respect to other business objectives. A definition according to EMAS (eco-management and audit scheme) [10] determines that "environmental management system means the part of the overall management system that includes the organisational structure, planning activities, responsibilities, practices, procedures, processes 
and resources for developing, implementing, achieving, reviewing and maintaining the environmental policy and managing the environmental aspects”.

Corporate environmental management is characterized by four attributes: a multidimensional orientation of the goals, a cross-corporate character, a crossfunctional character, and a proactive behaviour.

The most important regulations regarding environmental management systems are ISO 14001 [11] and EMAS.

\subsubsection{Environmental management system under DIN EN ISO 14001}

In 1993 the first efforts for a standardization system related to environmental protection were achieved by ISO (International Organization for Standardization) of the Business Council for Sustainable Development. In 1996 ISO 14001 was launched and republished as a new, improved version in 2004. EN ISO 14001 has become the international benchmark for environmental management systems, which can be used worldwide by all economic branches, and has been implemented in 138 countries.

The requirements to an environmental management system according to ISO 14001 are defined as a continuously improvement process running through the cycle of planning, implementation, controlling, and improvement.

\subsubsection{Environmental management system under EMAS}

The European Council adopted the Council Regulation (EEC) No 1836/93 [12], called EMAS, which is legally valid in all member states of the European Union. Companies now have the possibility to voluntarily participate in a standardized environmental management system and audit scheme. EMAS is an environmental management system based on legal regulations, while ISO 14001 is the result of private-sector standardization.

The requirements of ISO 14001 are core components of EMAS. Additionally EMAS calls for an "environmental statement" and special efforts regarding the compliance with all applicable legal requirements relating to the environment, the environmental performance, the external communication and relationships, and the employee involvement.

\subsection{Employee motivation}

Environmental protection and the concept of CSR can have positive effects to the employee motivation. Emotions, thoughts, awareness and unconscious actions, and automatic reactions are components forming the activity of human beings. A definition of motivation means the useful aspect of a bundling of these activities, which refers to the intensity of the behaviour, the quality and the direction [13]. The motivation provides insights into the motives of acting and behaviour of human beings. Motivation is generated by perceived stimulation conditions, which is the pre-requirement for target-oriented behaviour.

Motivation is a hypothetical creation, which means that the intervening variable between personal circumstances and observable behaviour is hardly or not directly measurable. But it is possible to observe input and output of the behaviour of an employee directly, which enables an empirical investigation. 


\subsubsection{Types of motivation}

In general it is distinguished between intrinsic and extrinsic motivation [14]. The latter cannot only be satisfied by the work or its environment, but by the result of the performance on the job. We know monetary motives, security motives and status motives. In the context of management, intrinsic motivation means that the motives of an employee can be satisfied by the work itself. It's differentiated between performance motives, competence motives, and sociality motives.

\subsubsection{Theories of motivation}

Motivation is an important topic in management and different theoretical approaches have been developed. Each theory concentrates on a different key aspect, distinguishing in content theories and process theories. The latter analyses, how motivation influences the behaviour, while the content theory focuses on the question, what generates motivation? We present the ideas of some of the most important motivation theories.

2.4.2.1 Maslow's hierarchy of needs This is a content theory and one of the oldest and renowned motivation theories worldwide. According to Maslow [15] the needs of human beings can be explained by five basic needs. First the physiological needs as a precondition for survival, like sleep, hunger and thirst. Second the personal safety regarding a secure livelihood and physical threats. Social affiliation is at the next level of Maslow's hierarchy of needs including love, friendship and partnership. These are followed by self-esteem, which means the personal feelings of achievement, and the need for recognition. On the top of the hierarchy we find the self-actualisation, like self-fulfillment and realisation of the own potential.

Under Maslow's hierarchy of needs the higher needs occur only when the respective lower need is satisfied.

2.4.2.2 Herzberg's two-factor-theory This theory is a content theory, as well. Herzberg [16] stated that job dissatisfaction and job satisfaction are not two specifications of one characteristic, but have to be considered as two independent variables. The two variables are the hygiene factors, showing the dissatisfaction, and the motivators, showing the job satisfaction. Hygiene factors can avoid dissatisfaction, but they cannot contribute to satisfaction (e.g. payment, personnel management policy, relationships between colleagues). Employees take these factors for granted, in case they are missing, it's perceived as a deficit. Compared to that, motivators can produce satisfaction. Motivators are related more to the job content than to job conditions (e.g. recognition, performance and success, responsibility, individual development).

By this theory Herzberg shows that on the one hand people look for development and self-actualisation, but on the other hand they try to avoid pain and reluctance. Compared to Maslow's theory, the two-factor-theory is empirically verified.

2.4.2.3 Vroom's expectancy theory Nowadays this theory [17] is the basis for all newer process theories. By means of this theory the dynamic of motivation 
processes in the organisational context can be demonstrated. People are more motivated acting in a specific manner, the more they expect a result from their individual action to be to their own benefit. Therefore the motivation depends on the characteristics of the personality of the employee, and the factors of the situation.

The theory can explain the most essential aspects of the employee motivation process, depending crucial on the combination of the organisational and individual goals.

2.4.2.4 Adams' equity theory This theory is also a process theory, and is based on balance thinking. Employees expect a fair compensation for their work. Adams [18] defines the inputs of the employee as education, intelligence, talents, loyalty, hard work and the outputs such as job security, esteem, salary, recognition, reputation, or responsibility. The comparison with the colleagues is important. The importance of determining motivation as a relative factor - on the basis of individual perception - is emphasised.

The validation of the equity theory, mainly concerning the salary, shows good results. One finding is the comparison with colleagues. A perceived imbalance can lead to a motivation to create the desired balance.

\subsection{Incentives}

As soon as a company grants immaterial or material compensations to people who are willing to contribute with time and other resources to the company objective, we talk about incentives [19].

The motivated behaviour of an employee can be activated for a concrete goal. If this goal is achieved, satisfaction arises. But each employee has different needs. Each behaviour or performance of an employee is connected to situational incentives. The incentives have an essential impact on the realisation of his or her motives. But before an employee is willing to make an effort to provide a specific performance, he or she balances up the compensation for his or her effort. We can understand this compensation as the incentive. Each behaviour of an employee is caused by a motive, and employees and their motives are influenced strongly by subjective perceived incentives. Additionally, motives of employees can change over time, e.g. the motive "reputation by hard work" can change to "more time for the family".

\subsubsection{Types of incentives}

This part gives a brief overview of the different types of incentives.

2.5.1.1 Material and immaterial incentives Material incentives are of monetary nature in the context of the job performance of the employee, like salary, bonuses, commissions, fringe benefits and profit sharing. Immaterial incentives are related to the job content and the work task of the employee, like self-fulfillment, social contacts and status, leadership, responsibility, and personal development. 
2.5.1.2 Incentives of the organisational environment These are the incentives of the entire environment of the organisation, perceived by the employee, and their influences on his or her willingness for performance and his or her satisfaction. Examples are the corporate culture, working atmosphere, and corporate concepts for environmental protection. For the latter it's essential that the employees can actually perceive them in their working environment. Corporate environmental protection has to be implemented, theoretical concepts themselves and lip services cannot stimulate incentives. This approach shows the importance of the connection between corporate concepts and corporate culture.

2.5.1.3 Incentive corporate culture The corporate culture reflects the values of the company internally as well as externally. A corporate culture with strong expressions of characteristics, with which employees can identify themselves, is a primarily positive motivation factor.

\subsubsection{Incentive corporate environmental protection}

According to the theories of incentives, corporate environmental protection can be classified as an incentive for employees, as far as the concept is adequately communicated and perceptible. If a company lives a well-developed corporate culture concerning environmental protection and sustainability, this can work as a motivation for employees.

Higher output through shared values between the company and the employees is one option for the influence of corporate environmental protection on the employee motivation. Due to an overlapping of the values of a corporate environmental protection concept with the values and expectations of the employees, a shared value is created. This can contribute to higher performance or willingness for performance of employees, and consequently increase the output of the company.

Another option is the increase of a company's attractiveness for qualified and motivated new employees, because of the incorporation of corporate environmental protection. Intrinsic motives of jobseekers can be activated.

\section{Empirical study}

The theoretical basis will now be applied on a practical example. A bank has been selected as a case study object.

\subsection{Kommunalkredit Austria AG}

Established as a specialist bank in 1958 to provide low-interest, long-term loans for Austrian local authorities, Kommunalkredit Austria AG today operates as its strategic core business in the field of public infrastructure finance and municipal project, focused on local authorities, municipalities, provincial governments and public institutions [20]. The bank's profile of services covers a broad range, from project consulting, budget management and asset management consulting to a wide variety of financing services. Kommunalkredit Austria AG leads projects in 
social infrastructure, energy, environment and transport to sustainable success. The company has approximately 300 employees.

\subsection{Census questionnaire}

Beside an intensive secondary analysis of documents concerning existing concepts and procedures, the main instrument of analysis was a survey. The questionnaire comprised twenty standardized (rating scales) and two open questions. The questionnaire covered all CSR related topics in order to find out, whether the activities of the company somehow influence the job motivation of the employees of the Kommunalkredit Austria AG or not.

\subsection{Findings}

The case study has shown that the company supports the environment with several entrepreneurial concepts. Hereinafter we will show if and to what extent this environmental and CSR related concepts, have an influence on the employees and their motivation.

\subsubsection{Corporate CSR policy and the consideration of sustainability in managerial processes}

As a public sector company, the Kommunalkredit Austria AG has a role model function regarding social and environmental values. The sustainability policy of the company includes important environmental protection principles for achieving and holding long term success and healthy economic growth. As the survey has shown this attitude was transferred to the employees and became part of the corporate culture and is certainly reflected in the corporate mission statement with the following wording:

"Our actions determine the holistic mental activity, i.e. the considerate and ecological aspects, the environmental compatibility and ethical criteria."

As long ago as 1997, EMAS (Environmental Management and Audit Scheme), an environmental management system had been introduced into the company. Based on this system a comprehensive sustainability management concept has been established. Since 2004 the company has published annual sustainability reports. For the bank and its employees this sustainability management system is not only an advertising tool but an embodiment for the whole organisational structure. Everybody, i.e. every employee is part of the system. This means, that sustainability in operations and a general corporate behaviour that adheres high corporate social responsibility standards are accepted at all levels of the company. According to the results of the survey employees live these CSR related values throughout their individual actions and take personal responsibility to achieve the goals.

\subsubsection{Energy and climate protection}

Renewable energies accounted about 65\% of overall energy consumption in 2010. Kommunalkredit Austria AG uses “green” electricity since 2003. “Green” 
electricity means, that the electricity is powered by "Naturstrom Plus" of Alpen Adria Energy AG. Naturstrom Plus is certified with the Austrian ecolabel. It is made up of $69 \%$ micro-hydro power plant, $30 \%$ wind and biogas electricity and $1 \%$ photovoltaic electricity.

For heat generation a wood pellets based heating system is in use. Advantages of the wood pellets based heating system are the reduction of $\mathrm{CO} 2$ emissions, a reduction of the greenhouse effect, as well as the stable price of the wood pellets in comparison to the oil price over the last years.

\subsubsection{Business trips and $\mathrm{CO}_{2}$ consumption}

Like most other companies, Kommunalkredit Austria AG generates unavoidable $\mathrm{CO}_{2}$ emissions (primarily by business trips and heating). For this reason the Kommunalkredit Austria AG compensates these emissions by sticking to the procedures of Climate Austria. "Climate Austria is a cooperation devoted to the voluntary offsetting of $\mathrm{CO}_{2}$ emissions. This is achieved by investing your voluntary contribution in climate protection projects, primarily in Austria and, upon request, also abroad". In this context $\mathrm{CO}_{2}$ compensation means that in the ideal case per ton $\mathrm{CO}_{2}$ emission caused by a company climate protection projects should be supported which avoid $\mathrm{CO}_{2}$ emissions on the same extent.

Remarkable in this context are the "business bicycles". The company provides bikes for its employees (several normal bikes and one e-bike). The idea was born from a working group on "sustainability in every day working life”. Members of this group suggested business bicycles be introduced for fast, healthy and environment-friendly work related journeys. This idea was adopted and implemented and has contributed to a culture where the car is left behind for short business trips.

\subsubsection{Resource, waste and recycling management}

Copy and printing paper in Kommunalkredit Austria AG are 100\% recyclable. All-in-one printers are used to reduce the wastage of paper. Additionally all of these printers have a default setting double-sided print only.

Further we have identified the following environmental friendly policies: the company uses environmentally friendly stationary only and the same applies to advertising material. For company events fair trade products are used exclusively.

The recycling and waste management system had been identified as a weakness, but the waste management system has been modernised recently (shortly after our study had been conducted).

\subsubsection{The staff's position}

Company activities on environmental protection and CSR are not only important from an ethical or to put it more pragmatic from a PR point of view it is important to the employees as well. If a company takes responsibility for its action e.g. in the environmental field the staff members transfer this attitude to other fields and regard the company as more thrust worthy. Therefore corporate concepts of environmental protection have a great impact on the motivation of a 
company's employees. The survey has also shown, that even job applicants are influenced by the CSR related behaviour of their future company.

Shared values concerning environmental protection, sustainability and corporate social responsibility have a highly motivating effect on the employees. It is important that entrepreneurs know, that they should be aware of this effect. By acting sustainable a company can generate an additional immaterial value for its employees. Employees are extremely interested in how their company is behaving in these fields and they acknowledge appropriate actions. We can say that according to our investigation environmental protection is a particular concern to the employees of the Kommunalkredit Austria AG and therefore we can confirm a positive relationship between acting environmentally sound and highly motivated staff members.

\section{Conclusion}

The empirical study revealed that environmental protection, sustainable management and corporate social responsibility in general are of particular importance for a modern company. These issues have a major importance for the employees and therefore a positive impact on the motivation of a company's staff.

Sustainable management and acting according to CSR values in general influences the external and internal image of a company as well as its corporate culture. Assessing the motivation theories, incentives of the organisational field and the corporate culture play a very important role for the employees. Companies which are aware of these facts can create a positive impact on their staff. It might be reasonably assumed that a reduction or a rejection of that corporate environmental protection produces an employee's discouragement.

Activities concerning environment protection and sustainability are often very cost-intensive. Therefore the company has to do everything to get a return on these investments. Often these returns are not of a financial nature, the enhanced employee motivation is certainly such a non-financial return. Therefore companies have to put high effort on emphasising environmental related topics in internal communications. The employees must know about these activities and have to recognize their value. Otherwise the positive impacts on employee motivation cannot be utilized.

Based on the example of Kommunalkredit Austria AG it could be demonstrated that the sustainability, environmental protection and corporate social responsibility are not only euphemisms. Employees take these issues very serious. The corporation's environmental protection measures regularly have positive effects on the employees of this particular company. Employees feel more comfortable and need not to have a bad conscience towards the environment if the company acts environmentally sound and communicates to its staff members accordingly. Acting according to the principles of sustainable management and CSR is an important input which a company's management can provide to its personnel. The result is an increase of the employee's motivation. 


\section{References}

[1] Pölzl, U., Umwelt-Controlling für Industriebetriebe, Dissertation, Graz, 1992.

[2] Bartik, D., Der Einfluss von unternehmerischen Umweltschutzkonzepten in Form von Coporate Social Responsibility auf die Motivation von MitarbeiterInnen am Beispiel der Kommunalkredit Austria, Thesis, Vienna, 2011.

[3] Crane A., Matten D., Laura J., Corporate Social Responsibility, a global context, Routledge, New York, 2008.

[4] Frederick, W.C. et al., Business and Society: Corporate Strategy, Public Policy, Ethics, $7^{\text {th }}$ ed., McGraw Hill, 1992.

[5] Schneider, A., Reifegradmodell CSR - eine Begriffsklärung und abgrenzung, in: Schneider, A., Schmidpeter, R. (eds.), Corporate Social Responsibility, Springer Gabler, Berlin Heidelberg, 2012.

[6] European Commission, A renewed EU strategy 2011-14 for Corporate Social Responsibility, COM (2011) 681 final, Brussels, 2011.

[7] Porter, M., Kramer, M.R., Corporate Social Responsibility, Harvard Business Manager, 29, 1-16, 2007.

[8] Ernste, D., Marktwirtschaft und Moral. Eine ordnungsethische Reflexion, Instituts-Verlag GmbH, Köln, 2007.

[9] Engelfried, J., Nachhaltiges Umweltmanagement, Oldenburg Wissenschaftsverlag GmbH, München, 2011.

[10] European Commission, Regulation (EC) No 1221/2009 of the European Parliament and of the Council of 25 November 2009 on the voluntary participation by organisations in a Community eco-management and audit scheme (EMAS), repealing Regulation (EC) No 761/2001 and Commission Decisions 2001/681/EC and 2006/193/EC, Official Journal of the European Communities, 2009.

[11] International Organisation for Standardization, ISO 14001:2004, Environmental management systems - requirements with guidance for use, http://www.iso.org/iso/home/store/catalogue_ics/catalogue_detail_ics.htm? csnumber $=31807$

[12] European Council, Council Regulation (EEC) No 1836/93 of 29 June 1993, allowing voluntary participation by companies in the industrial sector in a Community eco-management and audit scheme, Official Journal of the European Communities, 1993.

[13] Kaspar, H., Mayrhofer, W., Personalmanagement Führung Organisation, Linde Verlag, Wien, 2009.

[14] Hungenberg, H., Wulf, T., Grundlagen der Unternehmensführung, Springer Verlag, Berlin, Heidelberg, New York, 2007.

[15] Maslow, A.H., A Theory of Human Motivation, CreateSpace Independent Publishing Platform, 2013.

[16] Herzberg, F., One More Time: How Do You Motivate Employees?, McGraw-Hill Professional, 2008. 
[17] Vroom, V. H., Manage people, not personnel: motivation and performance appraisal, Harvard Business School Press, 1990.

[18] Adams, J.S., Inequity in social exchange, Advances in Experimental Social Psychology, 62:335-343, 1965.

[19] Rosenstiel, L., Motivation im Betrieb. Mit Fallstudien aus der Praxis, Rosenberger Fachverlag, Leonberg, 2001.

[20] Climate Austria, https://www.climateaustria.at/en/home/, 2013. 